\title{
Design and Implementation of 3 Axis CNC Router for Computer Aided Manufacturing Courses
}

\author{
Mehmet Emin Aktan ${ }^{1}$, Nihat Akkuş ${ }^{2}$, Abdurrahman Yılmaz ${ }^{3}$ and Erhan Akdoğan ${ }^{1}$ \\ ${ }^{1}$ Yıldiz Technical University, Department of Mechatronics Engineering, 34349 Istanbul, Turkey \\ ${ }^{2}$ Marmara University, Department of Mechatronics Engineering, 34722 Istanbul, Turkey \\ ${ }^{3}$ Istanbul Technical University, Department of Control and Automation Engineering, 34469 Istanbul, Turkey
}

\begin{abstract}
In this paper, it is intended to make the mechanical design of 3 axis Computer Numerical Control (CNC) router with linear joints, production of electronic control interface cards and drivers and manufacturing of $\mathrm{CNC}$ router system which is a combination of mechanics and electronics. At the same time, interface program has been prepared to control router via USB. The router was developed for educational purpose. In some vocational schools and universities, Computer Aided Manufacturing (CAM) courses are though rather theoretical. This situation cause ineffective and temporary learning. Moreover, students at schools which have the opportunity to apply for these systems can face with various dangerous accidents. Because of this situation, these students start to get knowledge about this system for the first time. For the first steps of CNC education, using smaller and less dan gerous systems will be easier. A new concept $\mathrm{CNC}$ machine and its user interface suitable and profitable for education have been completely designed and realize d during this study. To test the validity of the hypothesis which the benefits that may exist on the educational life, enhanced traditional education method with the contribution of the designed machine has been practiced on CAM course students for a semester. At the end of the semester, the new method applied students were more successful in the rate of 27.36 percent both in terms of verbal comprehension and exam grades.
\end{abstract}

\section{Introduction}

In some vocational schools and universities, Computer Aided Manufacturing (CAM) courses are though rather theoretical. Therefore, students face with ineffective and temporary learning. Besides, students at schools that have the opportunity to applying real Computer Numerical Control (CNC) machines, can face with various accidents. To eliminate these problems, various simulation systems are used. Before being applied to actual CNC machine, the corresponding meaning of the code written in simulation environment can be first observed on the virtual $\mathrm{CNC}$ machine. As a result, without being confronted with adverse accident which they may face while trying their own codes, students can make the necessary arrangements in a virtual environment. Thus, by applying a sort of debugging process to written code instead of making directly real-life testing of applications that actually confronted and observed, training more efficient and effective results with $\mathrm{CNC}$ machines are becoming possible. Starting from this situation, to accustom students to workbench in the first step of $\mathrm{CNC}$ training, creating a compact and relatively less dangerous system will have great help in education. There are several studies on this subject. Aktan, in his thesis, designed and manufactured low cost, three axis, multipurpose cartesian robot system for education [1]. Lee and Chang, in their study, have developed CAD/CAE/CAM system. They also stated that this system could be used as supplementary training tool in courses [2]. Köbeloğlu, in his thesis, designed and manufactured low cost, two axis, $\mathrm{CNC}$ lathe for training in vocational and technical schools [3]. Tseng and Kolluri, in their study, are designed microcontroller controlled 3 axis $\mathrm{CNC}$ router [4]. Their aim is was try out new technologies and use them in educational applications, especially. In this study, a compact, USB controlled 3 axes CNC router is designed and manufactured. An interface program is prepared with Microsoft Visual C\#. Un like other studies, the produced system has been tested on students. Mechanical design of the system is described in Section 2. In Section 3, electronics design is explained. User interface and control method are shown within the Section 4. Methodology and testing procedure are also described in Section 5. The results and conclusions are shown and discussed in Section 6 and 7, respectively.

\section{Mechanical Design}

The system has 3 linear axes. In these axes, transmission of motion is provided with the help of linear bearings. Radial movement which is produced by stepper motors, is transformed to linear movement by linear bearings. Stepper motors are linked to linear bearings via couplings. Axes are able to work independent from each other, at the 
same time interpolation process can be done with the concurrent movement of multiple axes. Technical properties of the router are shown in Table 1 and mechanical design of the router is shown in Figure 1.

Table 1. Technical properties of the router.

\begin{tabular}{|c|c|}
\hline Actuator Type & Stepper Motors \\
\hline $\mathbf{X}, \mathbf{Y}, \mathbf{Z}$ Limits & $500 \mathrm{~mm}, 400 \mathrm{~mm}, 180 \mathrm{~mm}$ \\
\hline Cutting Depth & $2 \mathrm{~mm}$ \\
\hline Cutting Velocity & $1 \mathrm{~m} / \mathrm{min}$ \\
\hline Free Velocity & $3 \mathrm{~m} / \mathrm{min}$ \\
\hline
\end{tabular}

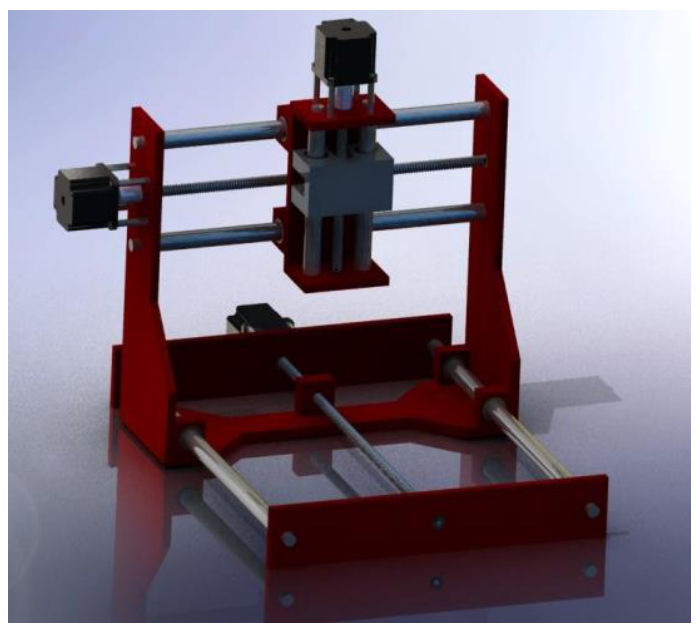

Figure 1. Mechanical structure of the router [1]

Necessary amount of motor power is calculated by regarding the general structure of the system and axes weight [5].

$$
\begin{gathered}
P=\left(2 \pi N_{m} T_{t}\right) / 60 \\
P_{a}=\left(2 \pi N_{m} / 60\right)^{2}\left(J_{L} / t_{a}\right)
\end{gathered}
$$

Where;

$P=$ Motor power while cutting $(\mathbf{W})$

$T_{t}=$ Total moment while cutting $(\mathbf{N m})$

$N_{m}=$ Motor speed (rpm)

$P_{a}=$ Motor power while acceleration (W)

$J_{L}=$ Total inertia $\left(\mathbf{k g}-\mathbf{m}^{\mathbf{2}}\right)$

$t_{a}=$ Acceleration time (sec)

As a result of calculations, findings about motor power requirements are pointed in Table 2 .

Table 2. Motor power requirements.

\begin{tabular}{|l|l|l|l|}
\hline & X Axis & Y Axis & Z Axis \\
\hline During Acceleration (W) & 16,03 & 13,47 & 5,77 \\
\hline During Cutting(W) & 30,16 & 15,07 & 39,57 \\
\hline
\end{tabular}

\section{Electronics Design}

The router has 3 stepper motors and for each stepper motor, drivers shown in Figure 2 were designed and produced. These drivers are combination of L297 and L6203. L297 is integrated circuit of stepper motor control. From step, direction and enable signals, which are given to input, it produces step motor phase signals at output. It can work at full step and half step modes. It is necessary to use adjunct integrated circuits like L298 and L6203 to drive motor with L297. L6203 is integrated circuit of Hbridge driver. There is one bridge inside. For this reason, to drive one stepper motor, it is necessary to use two L6203. It heats less and has ability to give current more in comparis on to L298. It can provide approximately up to 5 A output current.

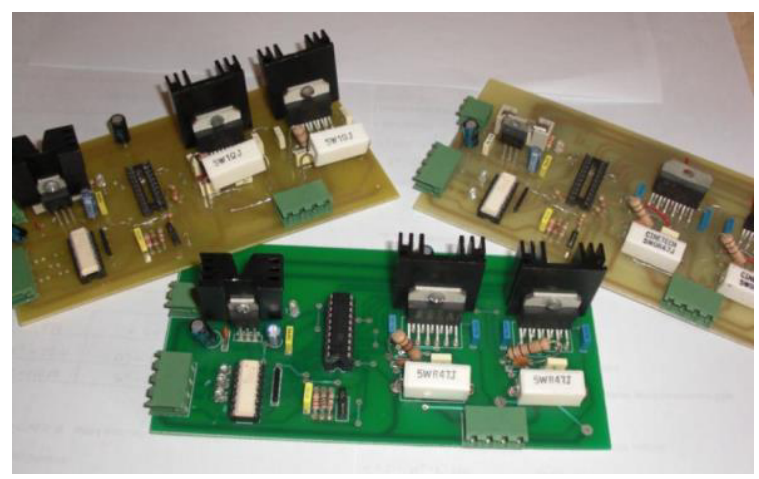

Figure 2. Motor drivers [1]

\subsection{Power Supply}

Full wave rectifier circuit is prepared as power source of motors. 300W 24 Volt transformer is used at circuit input. Rectification is managed with $1000 \mathrm{~V} 50$ ampere bridge diode at circuit output. $100 \mathrm{~V} 1000 \mathrm{uf}$ parallel capacitor is connected to output. Whole power supply circuit and its schematic drawing shown in Figure 3 and 4, respectively.

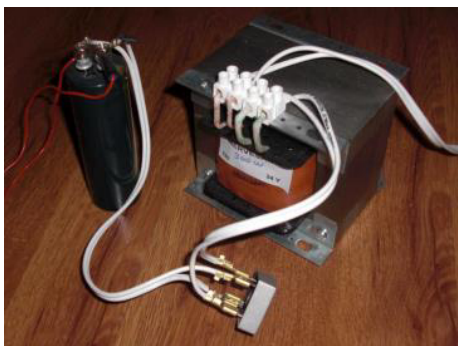

Figure 3. Power supply [1]

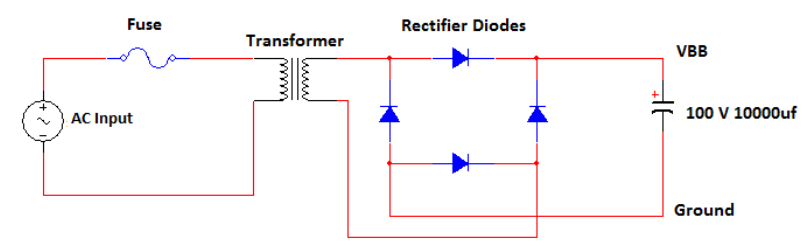

Figure 4. Circuit of power supply

\subsection{Control Box}


The control box (Fig. 5), which is consisting of electronic parts of the system, gives opportunity for user to make control and adjustment of processes. There are power source, driver and other electronic equipment inside the box. The front panel includes on-off switch, power indicator, axes movement indicators, X-Y-Z manual movement buttons, spindle switch and emergency stop button. The back panel has motor and limit switch connections.

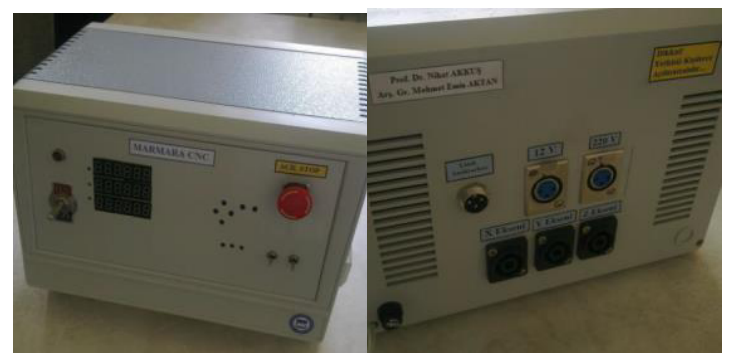

Figure 5. Control box [1]

\section{Interfaces and Control}

The router system's control type is open loop. By making essential calculations with microcontroller, number of steps are calculated and sent to L297 stepper motor driver. According to incoming signals, pulses are produced and sent to L6203 MOSFET driver. Necessary movements are carried out through driving motor with the help of driver. The block diagram of the system is shown in Figure 6.

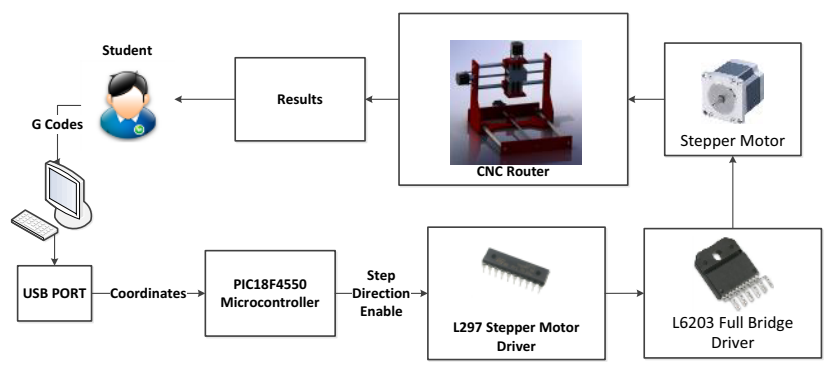

Figure 6. Block diagram

So far mechanic, electronic and program interface parts of system were mentioned. Now, it will be explained how the system works. Data trans mission is carried out via USB. So, the developed system is available to work on every computer that has USB port. The first step is the data analys is of $\mathrm{G}$ and $\mathrm{M}$ codes which are entered by user.

Our sample code is: "G01X97Y85"

In this code, $\mathrm{G}$ letter indicates working mode. What is to be done is determined according to the ensuring value. In our example, the value is 01 . Th is value signifies that router will start cutting process. Velocities of router at the time of cutting and going idle must be different. Because, while going idle, there is no force against and machine must be send to the place of cutting rapidly for time saving. Here, because of 01 value, axes should move slowly. Ensuring letter and the following number demonstrate which axes should move and the amount of movement in millimeters. According to the example, if the line had finished here, it would have been understood that we should go $97 \mathrm{~mm}$ in $\mathrm{X}$ axes at slow velocity. But it is seen that Y value is present next to X. It is the sign of linear interpolation to be done. After the line extraction in this process, velocity, axis and distance data are appointed to variables and send via USB channel to the microcontroller. Fro $m$ these incoming data, according to distance value which motor needs to take how many steps is calculated and pulses are sent to the driver. Through these pulses, motor rotates as required and a linear movement is performed via ball bearings. After end of the movement, microcontroller sends a signal to computer that the process is finished. Then, the computer sends values of next line to microcontroller. In this way, process finishes after all lines were processed.

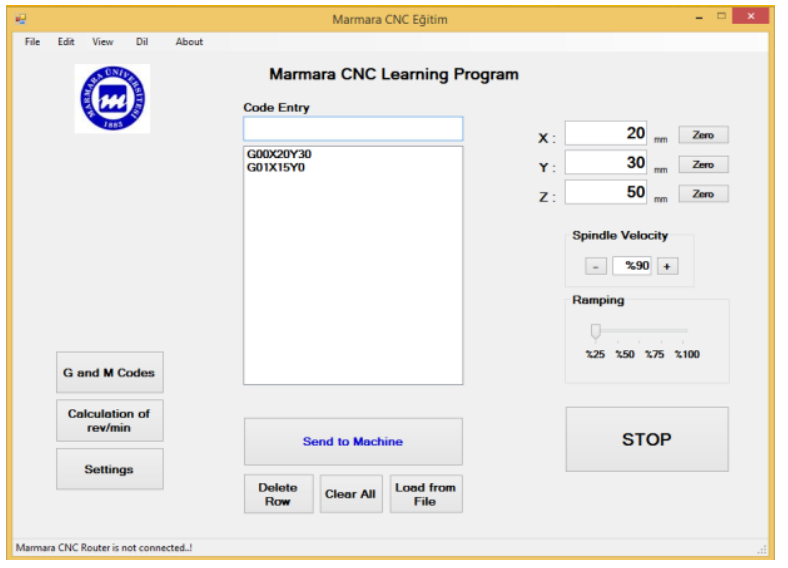

Figure 7. User interface [1]

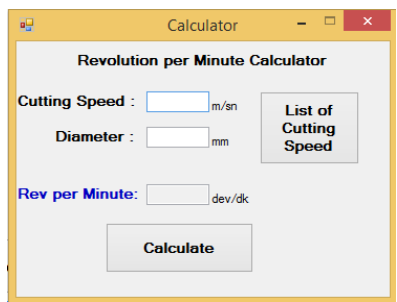

Figure 8. Revolution per minute calculator

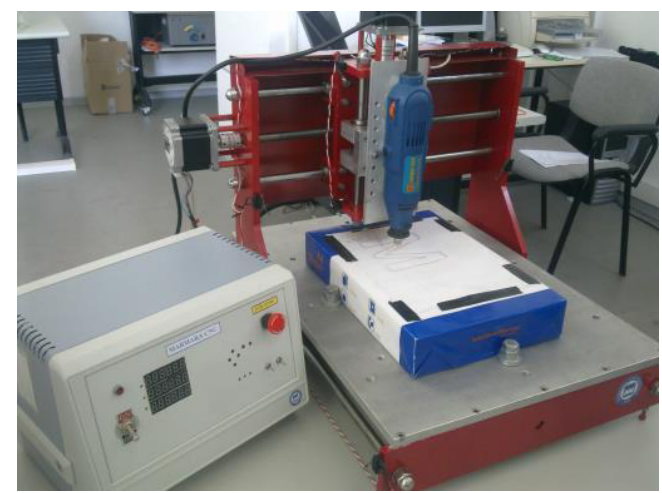

Figure 9. $\mathrm{CNC}$ router system [1]

The user interface which is written with Microsoft Visual $\mathrm{C \#}$ is shown in Figure 7. Here, $\mathrm{G}$ and $\mathrm{M}$ codes are 
entered from Code Entry section. The user writes the code and presses enter. The code passes the lower box. After all lines are written, the codes send to router by pressing "Send to Machine" button. By "Load from File" option, the code can also be downloaded from any text file. With indicators on the right side of the interface, can be seen the axis positions and by pressing "Zero" button, they can send to home positions. With the "Spindle Velocity" button, speed of the spindle can be adjusted. Required spindle speed can be calculated by pressing the "Calculation of rev/min" button on the left side of the interface. The calculator showed in Figure 8. From the ramping section, acceleration and deceleration ramping rate of the stepper motors can be set. In Figure 9, it is tried to visualize the entire mechanical design of the systemfor using CAM courses.

\section{Methodology of Testing}

After completing design and implementation of desired system, testing process the last step of the study has been started. During this step, the designed system has been integrated to CAM course taken by 96 undergraduate students and the aimed students are randomly divided into two groups. Addition to this, one of the groups was selected randomly and classic education methods applied during semester. The other group also had been educated via new, system integrated training scheme. In order to eliminate the effects of lecturer mentioned in the paper of Kane and et al [6], the in fluences of lecturing class size explained in Angrist and et al [7] study and also the possible impacts of lecturing at different times of a day, for both of the groups have been educated by the same lecturer at the same class and the same hours of the day. For comparing education methodologies during the semester two written and one oral examination including same kind of questions were applied to both groups. By averaging exam grades of the students, their semester-end scores were acquired.

The average semester - end grades of the students taken given CAM course can be seen as a bar graph in Figure 10. When the distribution of the grades between 0 and 100 investigated statistically, normal (Gaussian) distribution approximately has been achieved. The graph of average grades is clearly shaped like a Gaussian distribution. Due to the fact that any Gaussian distribution is a symmetrical distribution [8], skewness in other words coefficient of asymmetry should be equal to zero $[9,10]$. Kurtosis which means convexity is one of the characteristics for comparing any random distribution with normally distributed ones [9, 10]. Kurtosis coefficient is equal to 3 for Gaussian distributions $[9,10]$. As can be seen from Table 3, the parameters were calculated for obtained grades distribution as 3.1301 and 0.0648 respectively. Consequently, the distribution was roughly accepted in the form of Gaussian distribution.

On the other hand, so as to make the Gaussian distribution more meaningful and eliminate individual success or failure of the students, 95 percent was selected as confidence interval [11]. If the given Table 3 is examined, it has been also presented the whole class, end-average grade and standard deviation of the grades. By putting the average and standard deviation information to the given Equation 3 [11], the upper and lower boundaries of the confidence interval were derived as shown on Table 3. The boundaries of confidence interval and the eliminated students, emphasized by red color, with respect to them are demonstrated on Figure 10. The number of students eliminated due by confidence interval lower boundary and upper boundary, is 3 and 4 respectively. At this point, the students within the confidence interval were determined and listed in their groups. With final selection, average score calculation process for selected students was applied again in terms of their groups. Additionally, at the end of the semester a question concerning whether novel educational model are more efficient was directed by conducting a survey on related students.

$(\text { Confidence Interval })_{95 \%}=\mu \pm 1.96 \sigma$

$\mu$ : Average of distribution

$\sigma$ : Standard deviation of distribution

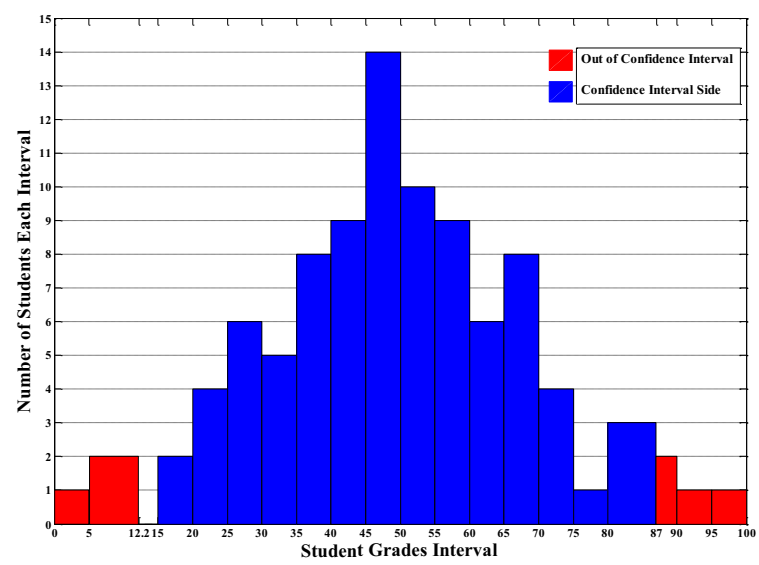

Figure 10. Semester - end grade averages of all students

Table 3. Main specifications of semester - end grades distribution.

\begin{tabular}{|c|c|}
\hline Number of Total Students & 96 \\
\hline Average Grades of All Class & 49.6017 \\
\hline Standard Deviation of Grades & 19.0719 \\
\hline Kurtosis of the Distribution & 3.1301 \\
\hline Skewness of the Distribution & 0.0648 \\
\hline Upper Boundary of Confidence Interval & 86.9826 \\
\hline Lower Boundary of Confidence Interval & 12.2207 \\
\hline $\begin{array}{c}\text { Average Grades } \\
\text { (New Method Applied Students) }\end{array}$ & 55.2209 \\
\hline $\begin{array}{c}\text { Average Grades } \\
\text { (Conventional Method Applied Students) }\end{array}$ & 43.3581 \\
\hline
\end{tabular}

\section{Results}


Targets were performed in educational 3 axis CNC router system and it was observed that system worked properly. Students trained by new method of learning had the opportunity of testing their experiences on real system during semester. Thanks to the recently designed $\mathrm{CNC}$ machine, without any accidents or injury the students reached to the end of the semester. Working with smaller and less detrimental system has encouraged the students to be self-confident and all students trained by new methodology has had the experience of conduct an experiment on real system at least once.

It is obvious that statistically obtained results are master indications of the study success. The evaluations at the end of the semester in terms of both exam grades and verbal dominance clearly show that the students trained by new method are $27.36 \%$ more accomplished than other students. Moreover the questionnaire made on modified learning process applied students results support the previous statistical outputs. As can be seen in Figure $11,64.44$ percent of the participants declared that new methods for learning are more efficient. The 24.4 and 11.12 percent of the participants also claimed respectively that no difference between new or classical methods, and backing up classical methods of education. When the obtained statements evaluated, it is deduced the new designed system used CAM courses will be more efficient and success ful.

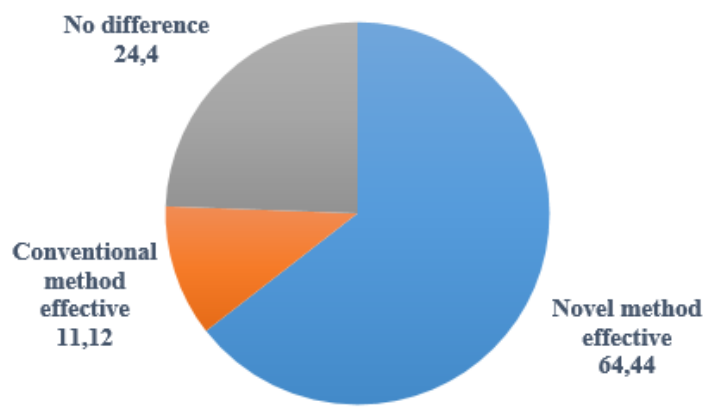

Figure 11. Questionnaire results on students

\section{Conclusions}

The students have difficulty to design or use real systems caused by the theoretical experiences in CAM courses. In order to overcome this problem, a novel methodology including simple and less dangerous CNC machine which is designed through this study was prepared and applied to CAM courses. A student group taken CAM course has been randomly divided into two groups. One of the groups was educated by traditional theoretical methods and the other one by recently designed method. The effects of the education methods have been tested by one verbal and two written examinations. The results show that new proposed and applied method to CAM courses is more efficient and successful in the rate of 27.36 percent. Also, the conducted survey outputs emphasize that new education methodology is widely acclaimed.

In order to improve proposed methodology and get suitable for any CAM course without any hesitation, several adding and regulations will be performed in further studies. Axis dimensions can be enlarged. Instead of step motors, more prec ision and powerful servo motors can be used. With the addition of divis or like structures, axis number can be increased and more varied geometrical shaped products can be processed. Open loop control can be converted to close loop control with the usage of encoders.

\section{References}

1. M. E. Aktan, Çok amaçlı 3 eksen Kartezyen robot sisteminin tasarımı ve imalat1, Master of Science Thesis, Marmara University, (2012)

2. H. S. Lee, S. L. Chang, Dev. of a CAD/CAE/CAM sys. for a robot man., Journal of Materials Processing Technology, 100-104 (2003)

3. A. Köbeloğlu, Eği. amaçlı masaüstü $\mathrm{CNC}$ torna tezgahı tasarımı ve prototipi, Master of Science Thesis, Karabük University, 1-6, (2011)

4. A.A. Tseng, S. P. Kolluri, A CNC machin ing system for education, Journal of Manufacturing Systems, 207-214, (1989)

5. M. Kutlu, "Üç eksenli masa tipi CNC freze tezgahı tasarım ve imalatı", Master of Science Thesis, Afyonkarahisar Kocatepe University, 39-42, (2006)

6. T. J. Kane, and O. S. Douglas, Estimating teacher impacts on student achievement: An experimental evaluation, National Bureau of Economic Research, (2008)

7. J. D. Angrist, V. Lavy, Using Maimonides' rule to est. the effect of class size on student achievement, National Bureau of Economic Research, (1997)

8. L.B. Castaneda, V. Arunachalam, D. Selvamuthu. Introduction to Probability and Stochastic Processes with Applications, Wiley, 151-161, (2012)

9. D. Doric, E. N. Do ric, V. Jevremovic, J. Malisic, On meas. skewness and kurtosis. Quality and Quantity, 43(3), 481 - 493, (2009)

10. L. Miodrag, International encyclopedia of statistical science, Springer-Verlag, 1012 - 1013, (2013)

11. W. C. Navidi, Statistics for engineers and scientists, McGraw-Hill Higher Education, 344 - 354, (2008) 